\title{
Judíos y conversos en las crónicas de los Reyes de Castilla (desde finales del siglo XIV hasta la expulsión)
}

\author{
RICA AMRÁN \\ Université de Nancy 2
}

En el presente trabajo pretendemos analizar la situación de la comunidad judia y judeo-conversa en los siglos XIV y XV, tal y como se nos presenta en las crónicas ${ }^{1}$.

Para ello vamos a estudiar las siguientes:

1. Crónica de Enrique III, ed. de Cayetano Rosell, BAE, 68 (1953), págs. 161-271.

2. Crónica de Juan II, ed. de Cayetano Rosell, BAE, 68 (1953), págs. 272-695.

3. Crónica de Enrique IV, de Alonso de Palencia, ed. de Paz y Meliá, BAE, I (1973), págs. 9-327.

4. Crónica de los Reyes Católicos de Fernando del Pulgar, ed. de Cayetano Rosell, 70 (1953), págs. 229-566.

5. Crónica de los Reyes Católicos de Andrés Bernáldez ed. de Cayetano Rosell, 70 (1953), págs. 567-773.

Las citas no son abundantes, por lo que hemos decidido incluirlas en su mayor parte en el texto. A través de éstas recordaremos la historia de ambas comunidades en tierras hispanas, y la visión de aquellos que las redactaron, claramente expresada en ocasiones, que nos darán a fin de cuentas, la opinión de la sociedad de su tiempo. Por todo esto, nos hemos permitido tratarlas en conjunto, pues creemos que están directamente relacionadas unas con otras como si fueran el relato del fin de la comunidad judía en Castilla, y la aparición de un nuevo elemento social, el converso, con toda la problemática que éste conlleva.

Hemos decidido estudiar las crónicas de finales del siglo xIV y del siglo xv, para ver cómo se efectúa el cambio de imagen del "judio" y del "converso". 
La primera crónica sobre la que vamos a trabajar es la de Enrique III, hijo de Juan 1 y de Leonor de Aragón, quien contaba solamente once años en 1390, a la muerte de su predecesor. Éste había dejado un testamento, que, por falta de acuerdo entre los grandes del reino, no se puso en práctica hasta el año $1392{ }^{2}$; Enrique sería coronado un año más tarde.

Lo que caracteriza toda la minoría de Enrique III es la inestabilidad política y social, suscitada por los diferentes bandos de la aristocracia, con el objetivo de debilitar el poder monárquico, en su solo provecho.

En la primera parte de esta crónica escrita por P. L. de Ayala ${ }^{3}$ refleja todos estos acontecimientos. La primera cita que encontramos sobre la comunidad judía es la que alude a las predicaciones realizadas por el Arcediano de Écija, Fernand Martínez, iniciadas en 1377, y que había creado una franca oposición por parte de Juan I y del cardenal Borroso. Así leemos:

\begin{abstract}
«En estos días llegaron á la cámara do el Consejo de los Señores é ca* balleros é Procuradores estaba ayuntado los Judios de la Corte del Rey que eran alli venidos de los mas honrados del Regno á las rentas que se habian entonce de facer, é dixeronles que avian avido cartas del aljama de la cibdad de Sevilla como un Arcediano de Ecija en la Iglesia de Sevilla, que decian Don Ferrand Martines, predicaba por plaza contra los Judios, é que todo el pueblo estaba movido para ser contra ellos. E que por cuanto Don Juan Alfonso, Conde de Niebla, é Don Alvar Peerez de Guzman, Alguacil mayor de Seviila, ficieron azotar un ome que facia mal á los Judios, todo el pueblo de Sevilla se moviera, é tomaron preso al Alguacil..." 4
\end{abstract}

Pero por desgracia, los fallecimientos de ambos, el cardenal y el rey, con muy poca diferencia de tiempo (el primero el 7 de julio de 1390, y el cardenal el 7 de octubre de 1390), llevan al poder a un menor, Enrique III, y dejan a Ferrand libre para continuar con sus maquinaciones:

2 LeROY, B.: Les juifs dans l'Espagne chrtiènne avant 1492, París 1992, págs. 19-36. VALDEÓN BaRUQue, J.: Enrique de Castilla, la guerra civil, y la consolidación del régimen (1366-1371), Valladolid 1966. SuáREz FERnÁNDEZ, L.: Judíos españoles en la Edad Media, Madrid 1980, págs. 201-205.

3 Pedro lópez de Ayala, llamado el canciller, 1322-1407. Vivió en la época de Enrique ll y Juan II, y en la minoría de Enrique III. Hombre activo en la Corte, destacó también en el área de las letras, en la que señalamos el "Rimado de Palacio" y las crónicas de Pedro I, Enrique II, Juan I y Enrique III, esta ültima sin terminar, y continuada por Alvar García de Santa María.

4 Crónica de Enrique III, pág. 167. 
"Ca antes que el Rey don Juan finase avia comenzado a predicar contra los Judios; é las gentes de los pueblos, lo uno por tales predicaciones, lo ál por voluntad de robar, otrosi non aviendo miedo al rey por la edad pequeña que avia, é por la discordia que era entre los Señores del Regno por la quistion del testamento, é del Consejo, ca non presciaban cartas del Rey, nin mandamientos suyos las cibdades nin villas nin Caballeros, por ende acontesció este mal segund avemos contado» 5

Las consecuencias se comprueban en el asalto de la judería de Sevilla ${ }^{6}$, el 6 de junio de 1391, lo que contagió a toda Andalucía, a Valencia (9/7/1391) y a Barcelona (5/8/1391):

"Despues que los que estaban con el Rey ordenados para regir por Consejo vieron que non podian acordarse con el Arzobispo de Toledo, magüer le avian tantos mensageros com avades oido, partieron de Madrid, é vino el Rey á la cibdad de Sevilla avia robado la Juderia, é que eran tornados Christianos los mas Judios que y eran, é muchos de ellos muertos. $E$ que luego que estas nuevas sopieron en Cordoba, é en Toledo, ficieron eso mesmo, é asi en otros muchos logares del Regno. E sabido por el Rey como los Judios de Sevilla é de Cordoba é de Toledo eran destroidos, como quier que enviaba sus cartas é ballesteros á otros logares por los defender, en tal manera era el fecho encendido, que non cedieron ninguna cosa por ello; antes de cada dia se avivaba mas este fecho: é de tal manera acaesció, que ese mismo ficieron en Aragon, é en las cibdades de Valencia, é de Barcelona, é de Lérida, é otros logares»?

Las razones de estas persecuciones fueron en palabras del propio cronista:

"E todo esto fue cobdicia de robar, segund paresció, mas que devocion»"

Alude también López de Ayala a que los causantes de aquellos actos desearon hacer lo mismo con los musulmanes, pero tuvieron miedo que ellos adoptaran idéntica conducta, en el reino de Granada o al otro lado del Estrecho, con los cautivos cristianos ${ }^{9}$.

Aparte de las citadas, hay dos más, relacionadas con el tema: la primera es al entrar en vigor el testamento del rey Juan, en el que él ordenaba:

Crónica de Enrique III, pág. 167.

4 de junio en la documentación hebrea.

Crónica de Enrique III, pág. 177.

Cronica de Enrique III, pág. 177. Ver también WOLFF, PH.: The 1391 progrom in Spain. Social crisis or not?, Past and Present, 50 (1971), págs. 4-18.

9 "E eso mismo qusieron facer los pueblos á los Moros que vivian en las cibdades é vilas del Regno, salvo que no se atrevieron, por quanto ovieron rescelo que los christianos que estaban captivos en Granada, é allende la mar, fuesen muertos". Crónica de Enrique III, pág. 177. 
«E todos estos dichos maravedies, asi de aniversarios, como de cera, é de aceyte, é de reparamiento de los ornamentos, que loshayan en la cabeza del pecho de los dichos Judios de la cibdad de Toledo, é que recudan con ellos al dicho Capellan mayor, par que los él despenda é distribuya en las sobredichas cosas» ${ }^{10}$.

La segunda, a la que hacemos alusión, es cuando decide hacer lo mismo que su padre, en su testamento, en cuanto a la cabeza de pecho de los judíos de la aljama de Toledo:

“E todos estos dichos maravedís, asi de aniversarios, como de cera é aceyte é reparamiento de los dichos ornamentos, que los hayan en las rentas é pechos que yo he, é los Reyes que después de mí vinieren ovieren en la dicha cibdad de Toledo..." ".

La descripción de los acontecimientos acaecidos en el trágico año de 1391 es escueta pero no deja dudas sobre su dureza. El cronista parece sorprendido de que un hecho como este pudiera ocurrir en su época. También es tajante al opinar que sí a Ferrand Martínez le cegaba la fe, a sus seguidores les movía la codicia.

La segunda crónica que vamos a estudiar es la de Juan II (1405-1454), quien subió al trono de Castilla al año $1414^{12}$. Más interesado por la música y la poesía, que por los asuntos del reino, confió a D. Álvaro de Luna el gobierno de Castilla ${ }^{13}$. Dicha crónica fue redactada en su mayor parte por Alvar García de Santa Maria ${ }^{14}$, y "ordenada» por Fernán Pérez de Guzmán.

La primera cita que encontramos en dicha crónica, relacionada con los judíos es cuando se nos habla de la llegada al reino castellano de Vicente Ferrer, su estancia en la corte y predicación:

"Estando el Rey é la Reyna y el Infante en Aillon, vino un Frayle en Castilla de muy sancta vida, natural de Valencia del Cid, que se llamaba Fray Vicente, de edad de sesenta años, que haia seydo Capella del Papa

10 Crónica de Enrique III, pág. 187.

"Crónica de Enrique III, pág. 265.

12 Hijo de Enrique III y Catlaina de Láncaster. Fueron regentes hasta su mayoria de edad: su madre y su tio Fernando (quien a partir de 1412 es rey de Aragón).

13 Juan II deja de su primer matrimonio, con Maria de Aragón (hija de Fernando de Antequera), tres hijas y un hijo, el futuro Enrique IV. De su segundo matrimonio con isabel de Portugal nacería la futura reina Isabel, y el príncipe Altonso.

14 Alvar Garcia de Santa María (1349-1356), hermano de Pablo de Santa Maria. Prestó servicio a los regentes D. ${ }^{-}$Catalina y D. Fernando. Encargado de la crónica de Juan II. Sobre este tema ver: Morales Muñız, Dolores Carmen: Alfonso de Ávila Rey de Castilla, Ávila, 1988. 
Benedicto... el qual asi en Aragon como en Castilla con sus sanctas predicaciones convertió á nuestra Sancta Fe muchos Judios é Moros, é hizo muy grandes bienes, é con su sancta vida dió exemplo á muchos Religiosos y Clérigos y legos, que se apartasen de algunos pecados en que estaban... $Y$ entre muchas notables cosas que este Sancto Frayle amonestó en sus predicaciones, suplicó al Rey é á la Reyna é al Infante que en todas las cibdades é villas de sus Reynos mandasen apartar los Judios é los Moros, porque de su contínua conversacion con los Christianos se seguian grandes daños, especialmente aquellos que nuevamente eran convertidos á nuestra Sancta Fe; asi se ordenó é se mandó é se puso en obra en las mas cibdades é villas destos Reynos. Y entonce se ordenó que los Judios traxesen tabardos con una señal vermeja, é los Moros capuces verde con una luna clara" ${ }^{15}$.

El dominico valenciano, que en un principio se sintió movido por la misericordia al conocer los hechos del año 1391, predicó de forma totalmente diferente a la de Ferrand Martínez, sin deseos de encender al pueblo y a llevar a éste, a posibles persecuciones. Encontramos, sin embargo, a partir de 1411-1412, un cambio en su conducta. «Y será entre estos años, tras su estancia en la corte, y la violencia que comienza a aparecer en sus discursos, cuando muchos judíos decidirán convertirse, por miedo a represalias similares a las de 1391. Las leyes de Ayllón, inspiradas por Vicente Ferrer, y apoyadas por la reina regente Catalina (2 de enero de 1412), la bula de Benedicto XIII (23 de enero de 1412), y la disputa de Tortosa (de agosto de 1412), vendrían a enturbiar aun más la situación de la comunidad judía de Castilla ${ }^{16}$. Sobre estos acontecimientos no hemos encontrado ninguna descripción en la crónica que estamos analizando. Creemos, a pesar de ello, que sin estos tres elementos, resultan dificilmente comprensibles los acontecimientos que se producirán en el siglo XV.

La crónica nos pasa a relatar las revueltas toledanas de 1449 contra los conversos 17: Don Álvaro de Luna había solicitado un «empréstito» a la población de Toledo, hubo negativa a la hora de desembolsar la cantidad de dinero demandada. Los recaudadores de la ciudad eran, en su mayoría, de origen converso. La víspera del día señalado para hacer el pago efectivo, la muchedumbre, excitada por los canónigos Juan Alfonso y Pedro López Gálvez, cayeron sobre la casa del poderoso mercader converso Alonso Cota, quemando y destruyendo todo lo que encontraron a

15 Crónica de Juan II, pág. 340. Los avateres del viaje y predicaciones de Vicente Ferrer nos lo relata más explicitamente. AMADOR DE LOS Rios, J.: Historia de los judíos de España y Portugal, reed. Madrid, 1984, II, págs. 397-433.

16 AMADOR DE LOS Rios, II, págs. 130-131. Él nos cuenta que hubo unos 15.000 judios convertidos en Aragón, y otros tantos en Castilla.

17 Crónica de Juan 1/, págs. 661-662. 
mano, iban encabezados por el bachiller Marcos García de Mazarambrós, apodado "Marquillos»; de allí pasarían al barrio de la Magdalena, donde vivían los mercaderes conversos ${ }^{18}$, que les hicieron frente:

«E el capitán de los converos era en Toledo uno que se llamaba Juan de cibdad que era un grand recabdador e rico e atrevido converso. Pero por cierto, pértiga de mala vid, ca después ovo algunos de su linage que se fueron a tierras estrañas, e se tornaron de cristianos judios..." ${ }^{19}$.

Continua la crónica de D. Álvaro de Luna describiendo, asimismo, la muerte de los insurrectos en la plaza de Zocodover ${ }^{20}$.

Pedro Sarmiento, quien se decia partidario del príncipe Enrique, se puso al frente de los amotinados. Este, por su situación privilegiada en el Ayuntamiento de la ciudad, consigue dictar el 5 de junio una sentencia estatuto, destituyendo a todos los conversos que ostentaban cargos públicos, pues eran «sospechosos en la fe». Aunque con posterioridad Pedro Sarmiento sería condenado a muerte por Juan $\mid{ }^{21}$, encontramos la dicha ordenanza como el primer precedente a los denominados "estatutos de limpieza de sangre» ${ }^{22}$.

L.a polémica surgida tras este hecho fue evidente, y aunque por parte de algunos conversos, e incluso doctores de la Iglesia, se elevaron voces para protestar contra dichos acontecimientos, el año 1449 marcaría la clave de la oposición entre cristianos viejos y nuevos ${ }^{23}$ dentro de una sociedad que, en lugar de intentar acogerlos en su seno, se empeñaba en acentuar aun más sus diferencias.

La crónica de Juan II no nos relata la situación de la comunidad judeo-conversa en estos años. Es evidente que para el cronista estos hechos carecian de importancia suficiente como para incluirlos en su in-

18 Benito Ruano, E.: El memorial contra los conversos del bachiller Marcos Garcia de Mora (Marquillo de Mazarambros), Sefarad, XVII (1957), págs, 314-351. ALONSO DE CARTAGENA, Defensorium Unitatis Christianae, ed. de Miguel Alonso, Madrid 1943. CANTERA Burgos, F.: Alvar Garcia de Santa Maria, Madrid 1952, págs. 165-168, 416-464. AMADOR DE LOS RiOS, III, págs. 118-119.

i9 Crónica de D. Álvaro de Luna, cap. LXXXIII, ed. de J. de M. Carriazo, Madrid 1940, pág. 244.

20 "Este Juan Cibdad murió mala suerte, en ruydo de vando que quiso sustentar de su judiego, e después de muerto fué colgado por los pies en la forca pública de la plaza de Çocodover. E allá se vaya su mal con él e dios le da mal sieglo; como es cierto que le no, e le dará para siempre, si non morió en la Fe del alto Jesus". Crónica de D. Álvaro de Luna, pág. 244.

21 Crónica de Juan II, págs. 674-675. Benito Ruano, E.: La sentencia estatulo de Pero Sarmiento y los conversos toledanos, Revista de la Universidad de Madrid, VI (1957), págs. 277-306. D. Pero Sarmiento, Repostero mayor de Juan II de Castilla, Hispania, 17 (1957), págs. 483-503.

22 LeROY, B.: op. cit, pág. 100.

23 Cantera, F.: op. cit., págs. 423-427. 
forme. Es por ello que debemos completar con otras fuentes paralelas. Será la crónica de Enrique IV de Alonso de Palencia, quien nos aclarará en este punto ${ }^{24}$ :

“...pero más, después que el terrible despojo de los conversos, acusados de apostasía, provocó los tumultos de Toledo. Este dió causa a que, so protexto de extipular las supersticiones introducidas por aquellos, excitados los ánimos de los plebeyos, se lanzasen al saqueo con tal furor, que temerosos luego del castigo de los crímenes perpetrados tuvieron que acogerse al amparo de D. Pedro Sarmiento, caballero de noble alcurnia, pero de depravadas costumbres, rebelándose osadamente contra la autoridad del Soberano. Este delito muy del agrado de D. Pedro López de Ayala...” 25.

Son varias las noticias, relacionadas con el reinado de Enrique IV, que encontramos en la crónica de Alfonso de Palencia sobre los tumultos acaecidos en Andalucía: el maquinador de la persecución de 1473 contra los conversos fue, según el ilustre cronista, Don Juan Pacheco, Maestre de la Orden de Santiago, quien deseaba sembrar la discordia y el desacuerdo, de ya enraizado, entre cristianos viejos y nuevos, quienes sólo coincidían en un punto, inclinarse a favor del partido de Isabel y Fernando. Pacheco inició sus intrigas en Córdoba, donde se quejaban de que los conversos se habian enriquecido de forma incomprensible, enfrentados de forma directa, "por su mala conducta», al arzobispo de Córdoba. Al parecer el populacho estaba dirigido por un herrero, Alonso de Aguilar, quien quería ayudar a éstos, alistando 300 soldados, pero cambió de idea, pasándose al bando de los cristianos viejos.

$Y$ los acontecimientos se desencadenan cuando al paso de una procesión, una muchacha conversa arroja agua por la ventana ${ }^{26}$, el herrero grita que es orin, y llama a la lucha contra los «herejes». Las persecuciones llegan a su máxima expresión el mes de marzo de 1473. Muchos de los conversos de la ciudad huirían a Sevilla, pidiendo permiso al duque de Medinasidonia para asentarse en Gibraltar (quien se lo concedió hasta el año 1476). El poeta converso Antón de Montoro escribiría a la reina

\footnotetext{
24 Alonso de Palencia nació en Osma el 21 de julio de 1423. Desde los diecisiete años hasta 1453 vivió en Italia, y hacia 1463 reside en Sevilla. Prácticamente participa en todos los acontecimientos importantes de su época: destronamiento de Enrique de Ávila; convenció al duque de Medina Sidonia a favor de coronar al príncipe Alfonso como rey, etc.Desterrado desde 1466, participa en la concordia de los Toros de Guisando, en el que se declaró heredera a Isabel.

25 Crónica de Enrique IV, pág. 12.

26 AmRAN, R.: Apuntes sobre los conversos asentados en Gibraltar, En la España medieval, XI! (1989), págs. 249-253. BAER, Y.: Historia de los judios en la España cristiana, Madrid 1981, II, págs. 552-553.
} 
Isabel sobre Alonso de Aguilar y "su traición" en los tumultos cordobeses, pidiendo a la reina ponga fin a estos desórdenes:

"sirviéreis el saco-mano de la villa de Carmona... el corazón vos manara gotas de muy gran piedad" ${ }^{27}$.

Alonso de Palencia nos lo cuenta de la siguiente manera ${ }^{28}$ :

“... sólo haré mención del ventamiento que contra los conversos, a quien tuvo por más hacedero entregar a las iras que las facciosa conjuración de los malvados, sedientos de sus riquezas, el apellido de religión; cual si ésta mandase el saqueo, el asesinato y la violencia perpetración de todo género de infamias, como lo habian hecho en Toledo, y como lo hicieron después los ladrones siguiendo el permicioso ejemplo.

Terrible y criminal fue el tumulto de Carmona, y bien hubiera necesitado rápido remedio; más como a $\mathrm{D}$. Enrique no quiso ponerle por consideración a D. Beltrán de la Cueva, que era hermano del alcaide Beltrán de Pareja, se echó mano de subterfugios para aparentar ciertas manera de castigo, el cual consistió en que saliese cierto Diego de Osorio, que se llamaba corregidor, con tropas de Córdoba y Ecija, y algunas de Sevilla, a contener algún tanto alos revoltosos, que no a entregar a cada uno lo suyo, según la verdadera definición de la justicia. este inicuo proceder fue causa de nuevas desdichas que, como explicaré, padece sin interrupción la villa de Carmona.»

Otra cita que encontramos en la crónica de Alonso de Palencia, es el enfrentamiento entre Enrique IV y su hermano el príncipe Alfonso. También los odios y rencores entre cristianos nuevos y viejos se verán reflejados ${ }^{29}$ :

"ya porque diese crédito al rumor, falsamente extendido enToledo y otras ciudades por los mal intencionados, de que a persuasión de los Grandes, D. Alfonso se disponía a perseguir a los conversos, acusados de prevaricadores y de abusar del culto y de la religión, de donde surgió nuevo y abundante semillero de discordias, ya deseminado desde los días de D. Alvaro de Luna. Buscaron pues los conversos favor en la facción de $\mathrm{D}$. Enrique, porque el espantoso recuerdo de los daños sufridos, y la previsión de los que les amenazaban, traía angustiados los ánimos de aquelia gente, y sentía la necesidad de procurarse algún amparo. El obispo de Calahorra mostrándose benévolo con el partido de los deudos del Deán, a que éste pertenecía, logró persuadirle fácilmente a que renunciase a sus antiguas predicaciones y retractándose de sus primeros consejos, defendiese por escrito la causa de D. Enrique...”

27 BAER, ibid, II, pág. 555.

2* Crónica de Enrique IV, pág. 136.

29 Crónica de Enrique IV, pág. 195. 
Una vez más observamos, en un momerito crucial, como resurgen los enfrentamientos entre estos dos grupos sociales: al difundirse el rumor de que el rey-niño deseaba el exterminio del judaísmo en sus dominios, los conversos decidieron apoyar al rey Enrique.

"Revivió por entonces entre los moradores de Toledo la antigua enemiga fomentada por los recelos de los cristianos nuevos y la indignación de los viejos.Agregábase a esto, com dije, la facción común de los conversos que, víctimas de las intrigas de los más intencionados, se inclinaban a don Enrique por el temor preconcebido del exterminio de la raza judaica en el caso de prevalecer el partido de D. Alfonso" ${ }^{30}$.

Otro ejemplo de que los conversos son empleados como "causa de odios y rencores", para atacar, a fin de cuentas, a algún noble, es el ejemplo que citamos a continuación:

"También creyó favorable a la defección de la ciudad el odio de los moradores al maestre de Santiago, cuya hija, la condesa de Medellín, estaba casada con el conde Cienfuentes, favorecedor, como dije, de los conversos, por lo que ambos cónyuges eran aborrecidos de los ciudadanos y de la plebe” ${ }^{31}$.

Volverá al cronista a aludir la guerra civil entre Alfonso y su hermanastro Enrique, la rebelión contra el primero de la ciudad de Toledo, y la vida de depravaciones que, al parecer, llevaría Maria de Silva ${ }^{32}$, mujer de Pedro López de Ayala ${ }^{33}$.

"Maria de Silva que, sobre la sensualidad del sexo, vivía entregada a excesos que ponian en peligro a la ciudad... al de una liviana mujer, rodeada de hechiceras, agoreros, moros y judíos que por sugestión del mismo D. Enrique y sus secuaces añadian maldades a maldades..."

Las crónicas hasta aqui tratadas, hacen alusión a la comunidad judía y conversa, especialmente en los momentos trágicos en los que estuvo en juego su superviviencia. Veremos el trato diferente que se les hace en las crónicas de los Reyes Católicos.

Fernando del Pulgar, en su crónica sobre Fernando e Isabel, al describir a esta última, entre sus muchas virtudes y cualidades, el autor nos dice:

30 Crónica de Enrique IV, pág. 215.

31 Crónica de Enrique $N$, pág. 247.

32 Crónica de Enrique IV, pág. 247.

33 Crónica de Enrique IV, pág. 249. 
"Esta Reyna fué la que estirpó é quitó la herejía, que había en los Reynos de Castilla é de Aragón, de algunos christianos de linage de los judios que tornaban á judeizar, é fizo que viviesen como buenos christianos" ${ }^{34}$.

Tras los acontecimientos de 1449, anteriormente citados, y la guerra civil entre los partidarios de Isabel y los de Juana la "Beltraneja", la situación de los conversos se va deteriorando, aun más si cabe. Encontramos dos tendencias dentro del mundo eclesiástico: el de hombres como Juan de Torquemada, Alfonso de Cartagena, etc., que defendían la necesidad de acoger en el seno de la sociedad a los conversos y no intentar alejarlos creyendo que todos son "sospechosos en la fe"; del otro lado encontramos a los defensores de la línea dura con fray Alonso de Espina ${ }^{35}$, que en su obra «Fortalitium fidei» recoge toda su doctrina. Esta última sería la que triunfa; todos los conversos que no han sido acogidos dentro de la sociedad cristiana, no fueron absorbidos por ésta, porque eran «malos cristianos», si hubieran sido verdaderos creyentes ésta les habría abierto sus puertas. De ahí la necesidad de crear la Inquisición, para poder saber con exactitud quienes siguen sus antiguos ritos y "castigar» la susodicha herejía, y para que los verdaderos conversos muestren su apogeo y devoción al cristianismo. Como consecuencia de todo esto, se decidió dar un plazo determinado (de un mes aproximado), en cada ciudad, a la que llegaba la Inquisición, para que se presentaran y se arrepintieran de sus «pecados» y confesaran libremente sus culpas.

En la crónica se nos habla de unas 15.000 personas, de las cuales 2.000 fueron quemadas vivos, mientras otros fueron castigadas con torturas físicas o a llevar cosidas a sus ropas los "sambenitos". Importante fue, evidentemente, la confiscación de los bienes de los acusados, que servirían para pagar los salarios de los propios inquisidores; el resto iría a las arcas de los Reyes Católicos, con lo que se sufragaria gran parte de la Guerra de Granada.

Debido a esta situación muchos conversos emigraron fuera de los reinos hispanos, llegando a Portugal, Italia o a Berbería. La consecuencia de esto, como vemos señalado en el texto, es la despoblación en tierras de Sevilla y Córdoba, suficientemente importante como para que esté descrito en la crónica.

34 Crónica de los Reyes Católicos, pág. 257.

${ }^{35}$ ¿Es él uno de los encargados por los Reyes Católicos, a la partida de estos de Sevilla, junto al Provisor Pedro de Solis y el Asistente Diego Merio, del establecimiento de la Inquisición? sólo se habla de un religioso de la orden de San Pablo, llamado fray Alonso. Crónica de los Reyes Católicos, pág. 331, nota 1. BEINART, J.: La Inquisición española y la expulsión de los judios de andalucia, Jews and Conversos, Studies in society and Inquisition (ed. Y.Kaplan), Jerusalem 1985 , págs. 103-123. 
Por último, y para terminar la explicación que se nos ofrece sobre la instalación de la Inquisición en Andalucía, y la expulsión de judíos en Sevilla y Córdoba, es que se llega a la conclusión de que la "mala conducta" seguida por los conversos se debe a la proximidad de sus "hermanos" de sangre, los judíos. Es decir, que los inquisidores creyeron que, a pesar de los castigos infligidos a los "pecadores", la situación continuaria siendo la misma: ¿no es, en parte, una victoria de esta sociedad conversa sobre el sistema inquisitorial, quien a pesar de sus muertes y castigos corporales y morales, llegan a la conclusión de no ser lo suficientemente fuertes para terminar con el criptojudaismo? ¿Habrían ellos comprendido ya, que su "solución al problema converso", sólo podía ser temporal y no total, por lo que deciden influir en los Reyes Católicos para expulsar a aquellos en quienes los "cristianos nuevos" podrían de nuevo verse reflejados? Aportamos por esto el texto, para que los lectores puedan llegar a sus propias conclusiones:

"Algunos Clérigos é personas religiosas é otros muchos seglares, informaron al Rey é á la Reyna, que en sus Reynos é señorios habia muchos christianos del linage de los judios, que tornaban á judayzar, é facer ritos judaycos secretamente en sus casas; é ni creian la fé christiana, ni facian las obras que cathólicos christianos debian facer... Esto sabido por el Rey é la Reyna, ovieron gran pesar, por se fallar en sus señoríos personas que no sintiesen bien de la fé cathólica, é fuesen hereges é apóstatas... Fray Tomás de Torquemada, Confesor del Rey, é Prior del monasterio de Santa Cruz de Segovia... este Prior que era principal Inquisidor, substituyó en su lugar Inquisidores en todas las mas cibdades é villas de los Reynos de Castilla... é ponian en ellas sus cartas de edictos, fundadas por derecho, para que aquellos que habian judayzado, ó no sentian bien de la fé, dentro de cierto tiempo viniesen á decir sus culpas, é se reconciliasen con la Santa madre Iglesia. Por virtud destas cartas y editos, muchas personas de aquel linage, dentro del término que era señalado, parecían ante los Inquisidores, é confesaban sus culpas é yerros que en este crímen de heregia habian cometido... Fueron estos mas de quince mil personas, ansi hombes como mugeres... Destos fueron quemados en diversas veces y en algunas cibdades é villas, fasta dos mil homes é mugeres; é otros fueron condenados á cárcel perpetua, é á otros fué dado por penitencia que todos los dias de su vida andoviesen señalados con grandes cruces coloradas, puestas sobre sus ropas de vestir en los pechos y en las espaldas... Vistas esta manera de proceder, muchos de los de aquel linage, temiendo aquellas execuciones, desapararonb sus casas é bienes, é se fueron al Reyno de Portugal, é á tierra de Igalia, é á Francia, é á otros Reynos... Fallárense especialmente en Sevilla, é Córdoba, y en las cibdades é villas del Andalucia en aquel tiempo quatro mil casas e mas, do moraban muchos de los de aquel linage; los quales se absentaron de la tierra con sus mugeres é fijos. E como quier que la absencia de esta gente despobló gran parte de aquella tierra..." ${ }^{36}$. 
La siguiente cita que encontramos en esta crónica es la convocatoria de las Cortes en el año 1480. Entre otras cosas se legislan leyes relacionadas con los judíos: que los judíos y moros viviesen separados en las ciudades y villas, sin relación con cristianos, que llevasen señales distintivas, la prohibición de adornar la Torá con oro y plata, etc. ${ }^{37}$.

El cronista nos habla de "por la qual confirmaronla ordenanza e constitución antigua, fecha por los reyes sus antecesores...» Sin embargo sabemos que, pese a la exigencia de estas leyes, estas no llegan a cumplirse con todo rigor, algunas como la que obligaba a portar distintivos a los judíos nunca fue aplicada en Sefarad, aunque vemos una vez más, su intento de imponerla.

La siguiente cita es del año 1485. En Toledo la Inquisición continuaba "su obra» de perseguir a los criptojudíos; la razón que se aduce es, según propia versión, la de no ser ni «buenos judíos", ni «buenos cristianos». El trabajo de la Inquisición fue remediar esto, por lo que se aceptaron cualquier tipo de testigos.

"Este año, continuándose la inquisición comenzada en el Reyno contra los christianos que habian seydo de linage de judios, é tornaban á judeizar, se fallaron en la cibdad de Toledo algunos homes é mugeres que escondidamente facian ritos judáicos. Los quales con grand ignorancia é peligro de sus ánimas, ni guardaban una ni otra ley; porque no se circuncidaban como judios segun es amonestado en el Testamento viejo. E aunque guardaban el sábado é ayunaban algunos ayunos de los judios, pero no guardaban todos los Sábados, ni ayunaban todos los ayunos, é si facian un rito no facian otro. de manera que en la una y en la otra ley prevaricaban; é fallose en algunas casas el marido guardar algunas ceremonias judáicas, é la muger ser buena christiana, y el tijo ser buen christiano, y el otro tener opinión judáica; é dentro de una casa haber diversidad de creencias, y encubrirse unos de otros. Destos fueron reconciliados á la fe muchos, é fueron recebidos á la Iglesia, é les fueron dadas penitencias é cada uno, segun la confesión que fizo. Algunos otros fueron condemnados á cárcel perpétua, é otros fueron quemados. É porque en este caso de la heregia se recebian testigos moros é judíos é siervos é homes infames é raeces, é por los dichos destos tales eran presos algunos é condemnados á pena de fuego, se fallaron en esta cibdad algunos judíos homes pobres é raeces que por enemistad, ó por malicia depusieron falso testimonio contra alguno de los conversos, diciendo, que los vieron judaizar. É sabida la verdad la Reyna mandó que fuesen justiciados por falsarios, é fueron apedreados é atenazados ocho judíos" ${ }^{38}$.

Crónica de los Reyes Católicos, págs. 354-355.

38 Crónica de los Reyes Católicos, pág. 432. LÓPEZ MARTinez, N.: Los judeizantes castellanos y la Inquisición en tiempos de Isabel la Católica, Burgos, 1954. KameN, H.: Historie de l'Inquisition Espagnole, Paris 1966. 
Pero lo que hemos encontrado más interesante es cómo se describen las predicaciones de Vicente Ferrer:

"un santo cathólico, varon docto de la orden de Santo Domingo, que quisiera en el aquel tiempo por predicaciones é pruebas de la Santa Ley é Escriptura convertir todos los judios de España, é dar cabo á la inveterada é hendionda sinagoga" ${ }^{39}$.

Vemos que el tono es diferente a aquel empleado en la crónica de Juan II, en la que se nos habla de la predicación de Vicente Ferrer, pero sin la agresividad y carácter ofensivo de la de los Reyes Católicos. Continuando en la misma línea, el cronista llega a la conclusión de que "contra negantes veritatem nulla est disputatio" ${ }^{40}$; en una palabra, está apoyando las persecuciones con el fin de que los judios se convierta, para evitar las malas influencias, aludiendo que la gran mayoría de los conversos «fueron y eran judios secretos, y no eran ni judios ni christianos pues eran baptizados, mas eran hereges" 41.

Esta es la clave de toda la teoria inquisitorial: "la herejía". Continuando con la cita, el cronista nos resume como los Reyes Católicos tomaron conciencia del problema:

"y estando el Rey la Reyna en Sevilla, la primera vez que á ella vinieron y el Arzobispo de Sevilla, Don Pedro González de Mendoza, Cardenal de España, había en Sevilla un santo y cathólico hombre, fraile de Santo Domigno en San Pablo llamado fray Alonso ${ }^{42}$, que siempre predicaba y pugnaba en Sevilla contra esta heregía; éste y otros religiosos y cathólicos hombres, ficieron saber á el Rey y á la Reyna el gran mal y heregía que habia en Sevilla; sometieron el caso al arzobispo que lo castigase y ficiese enmenda."

Después de la descripción de toda las razones para justificar las persecuciones, el cronista pasará a relatarnos la mala forma de vida de los conversos, sus hábitos y costumbres:

"Habeis de saber, que las costumbres de la gente comun de ellos ante la Inquisición, ni mas ni menos que era de los propios hendiondos judios, y esta causada la continua conversación que con ellos tenian; asi eran trago-

39 Crónica de los Reyes Católicos, pág. 599. El redactor será, a partir de la página 569, de esta crónica de los Reyes Católicos, también conocido como "el cura de palacios".

40 Crónica de los Reyes Católicos, pág. 599.

¿ Crónica de los Reyes Católicos, pág. 599.

42 Seguramente hace alusión a Alonso de Espina. 
nes y comilones, qu enunca perdieron el comer á costumbre judáica de majareros, é olletas de adafina, majarejos de cebollas é ajos, refritos con aceite, y la carne guisaban con aceite, ca lo echaban en lugar de tocino é de grosura por escuchar el tocino; y el aceite con la carne es cosa que hace muy mal oler e! resuelio; y ansi sus casas y puertas hedian muy mal á aquellos manjarejos; y ellos mesmos tenian el olor de los judios por causa de los manjarejos y de no ser baptizados" ${ }^{43}$.

Como vemos hace una relación entre las costumbres culinarias de los judios y el hecho de no estar bautizados, para pasar a la de los conversos:

"no comian puerco si no fuese en lugar forzoso; comian carne en las quaresmas y vigilias é quatro témporas de secreto; guardaban las pascuas y sábados como mejor podian; enviaban aceite á las sinagogas para las lámparas; tenian judian que les predicaban en sus casas en secreto, especialmente á las mugeres muy de secreto; tenian judíos rabies que les degollaban las reses é aves para sus negocios; comian pan cenceño al tiempo de los judios, carnes tajeles; hacian todas las ceremonias judáicas de secreto en quanto podiari; asi los hombres como las mugeres siempre se escusaban de recibir los sacramentos de la Santa Iglesia de su grado, salvo por fuerza de las constituciones de la Iglesia" ${ }^{44}$.

\section{Sobre su parentesco con cristianos viejos, se nos dice:}

"... algunos se mezclaron con fijos é fijas de cqballeros christianos viejos con sobra de riquezas que se hallaron bien aventurados por ello, por los casamientos y matrimonios que ansi ficieron, que quedaron en la Inquisición por buenos christianos é con mucha honra..." ${ }^{45}$.

Hace una diferencia, por tanto, entre aquellos que se relacionaron sólamente con sus antiguos correligionarios, y aquellos que casaron con cristianos viejos, pasando estos últimos a estar limpios de sospechas.

\section{Interesante es también el encabezamiento del capítulo número XLIV:}

"De como comenzaron en Sevilla á prender y quemar y reconciliar los hereges judáicos, é de la gran pestilencia del año ochenta y uno" ${ }^{46}$.

43 Crónica de los Reyes Católicos, pág. 599. Es interesante, aunque en época más tardia, por su relación con el tema: Domínguez Ortiz, A.: Los judeo-conversos en la España moderna. Madrid, 1992. Benito RuAno, E.: De la alteridad de la historia (discurso leído en la Real Academia de la Historia), Madrid 1988, págs. 47-94.

44 Crónica de los Reyes Católicos, págs. 599-600.

45 Crónica de los Reyes Católicos, pág. 600.

46 Crónica de los Reyes Católicos, pág. 600. 
En texto cabe subrayar, lo que creemos en una innovación en esta crónica, la de no hacer diferencia de hecho, entre "conversos" y "judíos", siendo sinónimos ambos del término «hereje»:

"Esta Santa Inquisición ovo comienzo en Sevilla, é después fué en Córdoba, donde habia otra tan grande sinagoga de malos christianos como en Sevilla" ${ }^{47}$.

Si seguimos las citas en un orden cronológico, tal y como lo estamos haciendo hasta el momento, encontramos la descripción detallada de los regalos realizados por los judíos de Zaragoza a los Reyes Católicos cuando estos estaban de visita en la ciudad. De un lado vemos la situación en el reino, desde el punto de vista doctrinal, de los conversos y judíos, del otro vemos como estos están en la Corte, son médicos, consejeros, etc., de reyes y nobles. $Y$ así con la misma naturalidad que el cronista nos cuenta los castigos ideados por la Inquisición contra aquellos conversos, 0 contra aquellos «malos cristianos» y "malos judíos", él nos decribe el presente y que "el Rey y la Reyna, puestos donde lo vieron todo, lo mandaron recibir é recibieron, é se lo tuvieron en muy gran servicio, é les dieron por ello muchas gracias é se lo agradecieron mucho" ${ }^{48}$.

En la última parte de la crónica, en la descripción de la expulsión, se comienza por explicar cuáles fueron las razones que llevaron a ella ${ }^{49}$, «la perpetua ceguedad de los judíos". Nos cuenta el número de judíos que salieron de Castilla y de Aragón, de como «los judios ricos hacian la costa de la salida de los judíos pobres, y usaban los unos con los otros en aquella partida de mucha caridad; ansi que en ninguna manera se quisieron convertir, salvo algunos muy pocos, de los más necesitados» 50 .

En relación a lo que ellos podían llevarse consigo, en su exilio de los reinos hispanos:

"a ovieron los christianos ca ovieron los christianos sus faciendas muy muchas, é muy ricas casas y heredamientos por pocos dineros, y andaban rogando con ellas, y no habia quien se las comprase, é daban una casa por un

47 Crónica de los Reyes Católicos, pag. 601.

48 Crónica de los Reyes Católicos, pág. 603.

49 En relación con la expulsión:

Beinart, H.: Historia de una tragedia: la expulsión de los judios en España, Barcelona 1993. Kriegel, M.: La prise d'une dècision: l'expulsion des Juifs d'Espagne, La Revue Historique, 527 (1978), págs. 40-90. Ladero QUESADA, M. A.: España en 1492, Madrid 1984. Ibid., el siglo XV en Castilla, Barcelona 1982. LeROY, B.: L'Espagne de Torquemada (catholique, juifs et convertis au xve siècle), París 1995.

${ }^{50}$ Crónica de los Reyes Católicos, pág. 652. 
asno, y una viña por un poco de paño ó lienzo; porque no podian sacar oro ni plata; empero es verdad que sacaron infinito oro é plata escondidamente, y en especial muchos cruzados é ducados abollados con los clientes, que los trabagan é sacaban en los vientres, ó en los pasos donde habian de ser buscados, ó en los puertos de la tierra é de la mar, y en especial las mujeres tragaban mas, cá a persona le acontecia a tragar treinta ducados de una vez" ${ }^{51}$.

Del destino de los dichos judios:

"Salieron de Castilla é entraron en Portugal con consentimiento del Rey Don Juan los siguientes; salieron por Benavente, tres mil ánimas y mas, que entraron en Portugal por Berganza' salieron por Zamora treinta mil animas á Miranda. que entraron en Portugal; salieron por Ciudad Rodrigo treinta y cinco mil ánimas, y salieron por Miranda de Alcántara á Maruan, quince mil; salieron por Badajoz á Helves diez mil ánimas. De los que estaban en frontera de Navarra, metiéronse en Navarra dos mil ánimas. De los que moraban en frontera de Vizcaya, entraron por Laredo en la mar, é de los Medina de Pumar é su tierra trescientas casas; y entraron por Cádiz en la mar ocho mil casas de los del Andalucía; é de los del Maestradgo de Santiago. Otros muchos fueron por Catajena é por los puertos de Aragón y de aquellas comarcas, é otros fueron á embarcar por los puertos de Aragon é sus confines. Los de los reynos de Aragon é Cataluña embarcaron por los puertos de Cataluña é Aragon, é entraron por la mar, y muchos de ellos entraron en la Italia, é otros á tierra de moros al reyno de Túnez é Tremecen é otros reynos, donde su ventura los echaba. Estos fueron los de los reynos de Aragon é de Cataluña, é los de Castilla, que embarcaron por los puertos de cartajena é confines del reyno de Valencia, de los quales los mas ovieron siniestras fortunas, robos é muertes en la mar y en la tierra por donde iban y arribaban, ansi de los christianos como de los moros" ${ }^{52}$.

Oponiéndose a las noticias de que los judios fueron bien acogidos en Fez, el cura de Palacios nos dice:

«por mandato del Rey de Fez, donde en el viaje eran robados por diversas maneras, é les tomaban las mozas, é las mujeres, é los lios de la hacienda, é echábanse con las mujeres á vista de sus padres é de sus maridos, faciéndoles mil plagas é mil desventuras; de manera que también los que estaban en Fez, puesto cargo que también allá habia muchos judios moriscos, también eran muy mal tratados y estaban desesperados; y sabido esto por los que iban... ${ }^{53}$.

51 Crónica de los Reyes Católicos, pág. 652.

52 No voy a entrar en la discusión del número de judios que salieron de Castilla, especialistas como Y. Baer, H. Beinart, M. A. Ladero Quesada o L. Suarez Fernández to han tratado. Sólo añadiré que me parece muy interesante la exposición de: SUÁREZ BILBAO, F.: Judíos castellanos entre 1432 y 1492. Ensayo de una prosopografía, Madrid 1990, 2 vols. (tesis doctoral).

53 AMRÁN, R.: El norte de África como refugio de judios y conversos españoles, HesperisTamuda (publ. de la Universidad de Rabat), en prensa. 
En su opinión, ante tanto sufrimiento, muchos judíos decidieron volver del reino de Fez, y tornarse cristianos para regresar al reino de los Reyes Católicos:

"e muchos se volvia de Fez, viendo la mala andanza de allá, de donde los del real sabian como los trataban. Alli, habido su acuerdo, se ficieron dos partes, la una se fué su via por el reino de $\mathrm{Fez}$, la otra parte demandaron al Conde de Borva, que estaba por Capitan general de Arcilla, que por amor de Jesuchristo, en el qual ellos creian, que los ficiese baptizar, é los ficiese volver a España; el qual los recibió echándoles agua con su bisopo por encima, que eran muchos, lo qual despues acá supimos los curas y los clérigos por donde vinieron, los quales despedidos de Arcilla por todo el año de 1493, desque comenzaron á dar vuelta á castilla, fasta el año 1496, no cesaron de pasar de allende acá en Castilla á volverse christianos» ${ }^{54}$.

Para terminar la descripción que hace sobre los judíos, y no deseando continuar con el tema, añade:

«porque seria prolijo y sin provecho escribir mas de estos judíos, no quiero aqui más de ellos escribir, salvo que en Fez el nuevo hicieron una muy grande juderia..." ${ }^{55}$.

Continúa narrándonos la historia de los judios en la ciudad de Fez, siendo esta la última cita que encontramos. Sólo cuando habla de la muerte de la Reina Isabel, añadirá, entre sus muchos atributos, que:

"viendo los inconvenientes y daños que procedian de los judios y moros à los catholicos christianos, desterró á los judios de España para siempre jamás, é hizo convertir los moros por fuerza é tornar christianos" ${ }^{56}$.

\section{A MODO DE CONCLUSIÓN}

Tras el estudio detallado de las crónicas, las cuales son la base del presente artículo, creemos interesante señalar:

1. Las comunidades judias y conversas son parcamente citadas en las crónicas. Sólo se hablará de las mismas en caso de que algún trágico suceso les acontezca.

54 Crónica de los Reyes Católicos, pág. 654

55 Crónica de los Reyes Católicos, pág. 655.

56 Crónica de los Reyes Católicos, pág. 722. 
2. Hemos encontrado un número de diecisiete citas sobre judíos y doce en el que se habla de conversos. El número es superior en las del siglo xv, especialmente en el reinado de los Reyes Católicos: diez amplias, explicativas sobre los judios, y cinco sobre la conducta de los conversos.

3. El razonamiento en las crónicas sobre las dichas comunidades es:

a) Razón del hecho.

b) Hecho propiamente dicho.

c) Conclusión o consecuencia, la cual siempre suele ser la misma (en el caso de los judios, por su ceguedad ante la verdadera fe; en el caso de los conversos, por ser «malos cristianos»).

4. No encontramos descripción de hechos positivos realizados por judíos, como podrían ser su intervención en la política del reino, como embajadores de la corona a otros países, o bien su actuación en la corte. Las citas relacionadas con conversos, las positivas, tienen un carácter doctrinal, cuando estos se oponían a sus antiguos hermanos de sangre, desde un punto de vista dogmático.

5. A pesar de todo, debemos tener en cuenta que los judíos, por su relación con la Corona, son atacados para disminuir su poder.

6. En las crónicas del siglo $x v$, las estudiadas, encontramos un cambio en el tono de las mismas, son más duras, más agresivas; en el lenguaje, cuando se habla de la comunidad judía, a la que prácticamente se les acusa de ser causantes de casi todos los males del reino (por supuesto, también el inducir al mal a sus antiguos correligionarios, los conversos), leemos adjetivos como: "hendían como judíos", «hendionda sinagoga", "descomulgado talmud", "falso libro del Talmud", "costumbre judaica de manjarejos", etc.

7. Creemos que las diferencias que se habian hecho al relatar a las comunidades judías y conversas no se encuentran en las crónicas del siglo xv. Desde nuestro punto de vista, incluso para el cronista, resulta difícil poder distinguir entre ambas, ¿o quizás lo hagan de forma intencionada?

8. Y para terminar si nos preguntamos a quién benefició la expulsión de la comunidad judia de suelo hispano, la respuesta es siempre la misma, a aquellos quienes se atribuyeron los bienes confiscados a estos. Evidentemente el motivo religioso era importante, el de alejar a los conversos de sus antiguos hermanos de sangre, y según estaba la situación en aquellos momentos en el reino, muy probablemente esta podía haber 
sido más grave que lo acaecido en el año 1391. Pero que dicha causa no nos haga olvidar que a la salida de los judíos de Sefarad, sus bienes y posesiones fueron a engrosar las arcas del reino.

Estas son las principales conclusiones a las que hemos llegado; somos conscientes que otras muchas pueden derivarse, tras la interpretación de las mismas, de estas u otras crónicas contemporáneas. Todas ellas nos ayudarán a completar la imagen de la situación social de judíos y conversos durante el siglo XV. 